\title{
Proposal of a Spatial Decision Support System architecture to estimate the consequences and costs of small meteorites impacts
}

\author{
E. Garbolino ${ }^{1}$ and P. Michel $^{2}$ \\ ${ }^{1}$ Mines ParisTech, CRC, 1 rue Claude Daunesse, BP 207, 06904 Sophia Antipolis, France \\ ${ }^{2}$ Université de Nice Sophia-Antipolis, CNRS, Observatoire de la Côte d'Azur, UMR 6202 Cassiopée, BP 4229, \\ 06304 Nice Cedex 4, France
}

Received: 20 April 2011 - Revised: 29 July 2011 - Accepted: 1 August 2011 - Published: 11 November 2011

\begin{abstract}
On a frequency, depending on their size, small celestial bodies enter into the Earth atmosphere and collide with our planet. On a daily basis, the size is likely to be about $20 \mathrm{~cm}$, while for monthly events the largest it may be is about $1 \mathrm{~m}$. The last significant witnessed event occurred in 1908 in the Siberian area of the Tunguska. The forest was devastated over an area of $2000 \mathrm{~km}^{2}$. According to recent estimates, this kind of event could occur with a frequency of one per hundred to thousand years. Since the last century, the demography and the urbanisation have significantly increased. Although the probability that such an event occurs over a populated area remains small, if this happened, it could cause significant damages (industrial, shopping centres, recreational places, etc.). From the analysis of the data on meteorites that have impacted the Earth, of the orbital and size properties of small threatening bodies as well as their potential impact outcome, this paper proposes a methodology to estimate the damage resulting from the impact of objects of given sizes. The considered sizes are up to the maximum threshold for local damages (less than a hundred metres in diameter) on some given territory. This approach is based on an initial definition phase of collision scenarios. Then, a second phase consisting of the accurate modelling of the territory, taking into account the land-use, the spatial distribution of the populations and goods, and the characterisation of the biophysical vulnerability of the stakes using thresholds of dangerous phenomena (overpressures). The third phase is related to the impact simulation on the territory, the estimation of the stakes potentially exposed and the costs of the destruction. The aim of this paper is to make a demonstration of principle, using as a study case the city of Nice that benefits from a complete database of infrastructures.
\end{abstract}

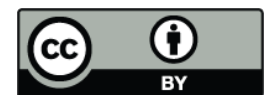

Correspondence to: E. Garbolino (emmanuel.garbolino@mines-paristech.fr)

\section{Introduction}

The identification of impact craters on the Moon as well as on the terrestrial planets, including the Earth, have provided evidence that the population of Near-Earth Objects (NEOs hereafter) represents a hazard of global catastrophe for human civilization. Several studies in the late 20th century (Alvarez et al., 1980; Toon et al., 1997) confirmed that small celestial body impacts onto the Earth can provoke an Extinction Level Event (E.L.E.) characterised by massive destructions that could induce the collapse of the human society and the destabilization of the global environment. Due to this level of consequences, the community of astronomers and astrophysicists is developing methods, tools and models to obtain accurate knowledge about the population of asteroids and comets, and in particular to identify the hazardous ones (French, 1998; Poveda et al., 1999; Chapman 2003; Morrison et al., 2002; Michel et al., 2005; Bottke 2007; Schweickart et al., 2008). This international community has organised a global network aimed at discovering and followingup these NEOs, paying particular attention to the groups of ECAs (Earth Crossing Asteroids) and ECCs (Earth Crossing Comets) (Morrison 2007; Valsecchi and Milani Comparetti 2007).

The last significant event recorded by human witnesses occurred in 1908 in the Tunguska (Siberia). This event is commonly interpreted as being due to the entry of a small body followed by its disruption in the atmosphere. According to Chyba et al. (1993) and Hills and Goda (1993), the object exploded at an altitude of $10 \mathrm{~km}$ and had a diameter of around 60 to $100 \mathrm{~m}$, depending on its assumed density and material strength. But more recently, Boslough (2009) using a supercomputer from the Sandia National Laboratories, suggested that the Tunguska event was provoked by an objet of about $25 \mathrm{~m}$ in diameter exploding at 7 to $8 \mathrm{~km}$ of altitude. This finding raises the inevitable problem of the impact frequency estimate of such Earth-crossing objects: indeed, according

Published by Copernicus Publications on behalf of the European Geosciences Union. 
to Harris (2009), the impact frequency of a $70 \mathrm{~m}$ diameter object is about one per millennium, but it becomes 1 per century for a $30 \mathrm{~m}$ diameter object. Other authors estimate that the frequency of Tunguska-like events is on average every $500 \mathrm{yr}$ (Bland and Artemieva, 2006).

In this context, this paper aims at presenting, after the introduction of a model of territorial vulnerability, the definition of a Spatial Decision Support System (SDSS). This allows the estimating of the impacted stakes in terms of fatalities and costs resulting from a small celestial body impact. The components of the architecture of this SDSS are described. The results take into account four scenarios involving a small NEO whose diameter is less than $100 \mathrm{~m}$. This choice of small bodies is justified by the fact that the number of NEOs increases markedly with decreasing diameters of the objects, and consequently, the probability of a collision with Earth also increases dramatically. Small asteroids in the hundred-metre size range are faint and, therefore, particularly difficult to detect, except perhaps on their final plunge. Of course, the probability that a small object collides on a specific small area, such as the region of Nice, cannot be compared to the probability of its collision with the Earth in a random location. Nevertheless, as it is demonstrated in this paper, if such a collision occurred in a region like Nice for which we have a complete database of infrastructures, it might induce damages important enough for the human society and the environment (Hills and Goda, 1998). This exercise could then be applied to any area for which such a database exists.

\section{Territorial Vulnerability: proposal of a characterisation model}

The term "vulnerability" comes from Latin "vulnerabilis" meaning "which can be wounded", "which wounds" and it is also the synonym of "sensibility". Mainly used in medical sciences, the concept of vulnerability was gradually introduced into the field of natural and technological risks in order to underline the capacity of an event to destroy structures and cause fatalities. The analysis of the use of the term vulnerability is in fact not dissociable to that of the concept of risk. In this respect, Brooks (2003) points out some references concerning the definition of the concept of risk and, more particularly, that borrowed from Crichton (1999), which reveals the term vulnerability. Along the same lines, the ISDR (International Strategy for Disaster Reduction) of UNO (United Nations Organisation, 2004) defines the risk as follows:

"The probability of harmful consequences, or expected losses (deaths, injuries, property, livelihoods, economic activity disrupted or environment damaged) resulting from interactions between natural vulnerable or human-induced haz- ards and vulnerable conditions. Conventionally risk is expressed by the notation

Risk $=$ Hazards $\times$ Vulnerability.

Some disciplines also include the concept of exposure, referring particularly to the physical aspects of vulnerability. Beyond expressing a possibility of physical harm, it is crucial to recognize that risks are inherent or can be created or exist within social systems. It is important to consider the social contexts in which risks occur and that people, therefore, do not necessarily share the same perceptions of risk and their underlying causes." This equation can be expressed numerically by replacing the term "Hazard" by the probability of occurrence of an event and the term "Vulnerability" by the amount of exposed people, buildings, etc. The risk can then be quantified and, for a given set of scenarios, the decision makers can prioritise their actions according to the risks incurred.

Thus, Brooks (2003) proposes to distinguish between two types of vulnerability for a given territory:

- The biophysical vulnerability: its definition is related to the level of damage of the stakes, whether human or material. It, therefore, depends on the physical impact of the hazard on the stakes, as well as on its intensity and on its frequency. This vulnerability is also similar to the "sensitivity" to the hazard of the considered system. The use of the thresholds for lethal effects, for example, makes it possible to characterise the biophysical vulnerability of the population on a given territory;

- Social vulnerability: it represents the capacity of a system to face a dangerous event, which is quite close in this case to the definition of resilience. A system is, therefore, more or less vulnerable and, a fortiori, resilient if it is able, at least partly, to face the adversity. Social vulnerability is then different from the biophysical vulnerability by the fact that it does not depend solely on the frequency and the intensity of the hazard but also on the property of the system which makes it more or less vulnerable: the recourse to the insurance of goods, for example, is a factor making it possible to reduce the vulnerability of a system because it allows a compensation for the losses induced by a hazard.

On the basis of these definitions, our approach, therefore, seeks first to determine the components of the territory and, secondly, to identify and characterise precisely those having an influence on the vulnerability and the resilience of the territory. Thus, from all the data and the technical means and procedures, the definition of the territorial vulnerability, as suggested here, can consider the following elements (Garbolino et al., 2009, modified):

- the intensity of the considered dangerous phenomenon (crater diameter and depth, overpressures, etc.). It depends mainly on the characteristics of the projectile 
(density, velocity, angle, nature, etc.), the surface conditions of the target and the dynamics of the event;

- the probability of occurrence of the hazard (small body impact) on the considered territory. It depends on the observations and the models (size and orbital distribution) of the NEO population, and on the surface area of the territory compared to the whole Earth surface

- the sensitivity (biophysical vulnerability) of the stakes facing the dangerous phenomenon considered. This parameter depends on the nature of the stakes, their state, their proximity to the dangerous phenomenon, etc.

- the resilience factors allowing the exposed stakes to return to a state close to their original one. They may include the proximity to health care centres, the good response of the emergency actions, the recourse to the compensation for the goods. It depends also on the detection capacity of the hazardous object in order to prepare the society for such an event, etc.

- the factors of aggravation of the dangerous phenomenon considered. They may include domino effects on structures causing in turn dangerous phenomena (for example, a toxic atmospheric release from an industry), the paralysis of the emergency network (roads, communication facilities, etc.), the contamination of vital resources (drinking water network, cultures etc.), the disorganisation of the Civil Protection, etc.

These various parameters allowing the characterisation of the vulnerability of a territory must be taken into account in their space-time dynamics on the considered territory. The following point proposes the definition of a SDSS prototype to face the risks and consequences of a small celestial body impact.

\section{Definition of a Spatial Decision Support System to as- sess the consequences of small meteorites impacts}

According to Jean-Jacques Chevallier (1993, 1994) "a SDSS aims at supporting a complex activity or a scenarii elaboration and evaluation process, in order to identify the best actions according to a situation, objectives and criteria. So, in addition to the functionality of a GIS, a SDSS should integrate mechanisms that allow us:

- to identify, describe and manipulate a set of decision data such as actions, scenarios, assessments;

- to jointly use the original data and various representation forms;

- to link spatial databases and specialized software to simulate and to analyse the specific problem studied;
- to have means to evaluate and compare scenarios, and then select one using the techniques of multi-criteria analysis."

Such a SDSS is aimed at helping the decision makers in their expertise of risk prevention and crisis management regarding a small body impact event and consequences. Figure 1 presents a prototype of SDSS dedicated to this topic. It shows the various components of this SDSS and tries to indicate the relationships between them. The various steps for application of this prototype are explained hereafter.

The first stage consists in both gathering and integrating the data on the elements that compose of the territory such as the road network, the population, the buildings, the cars density (1) etc. These data are then integrated into a Geographical Information System (GIS) in order to provide a spatial representation (2). All these spatial data are then used by the model base that also integrates the statistical and observed data concerning NEOs, and especially the hazardous ones (3). The model base produces two types of results that can be mapped (4):

- the distances calculation of the hazardous phenomenon caused by the impact on Earth of a small body (crater dimensions, blast effects, etc.). The simulations of NEO impacts have been computed using the models developed by Holsapple (1993a, b, 2003) and the equations from Glasstone and Dolan (1977);

- the estimate of the exposed stakes (population, buildings, cars, ERP - Establishments Receiving Public, Seveso Industries, etc.) according to the impact simulations.

These results are then transferred to a server (5) whose function is to capitalize them. In our study, these results aim at supporting insurance and reinsurance companies in their activity of risk assessment of their portfolios. In this context, this SDSS allows us to understand the vulnerability of theses companies according to the different scenarios of NEO impacts in a dense urbanised area in France. This prototype represents a reflection frame to help the insurance and reinsurance companies to define a strategy in order to face this threat. This strategy could take the form of the constitution of financial provisions or a fundraiser to participate to the deflection/destruction strategy of the hazardous NEO.

This SDSS can also contribute to help the public decision makers, especially the Civil Protection and the Government, to prepare Specific Emergency Plans, like they do for other natural disasters (volcanic, seismic, flood ones). On the basis of the most probabilistic scenarios, this SDSS gives to the Civil Protection the means to prepare their training sessions. In the case of a potentially hazardous NEO whose impact would be imminent, this kind of SDSS can help the crisis management and the post-crisis management who will benefit from the use of the simulation of the NEO impact 


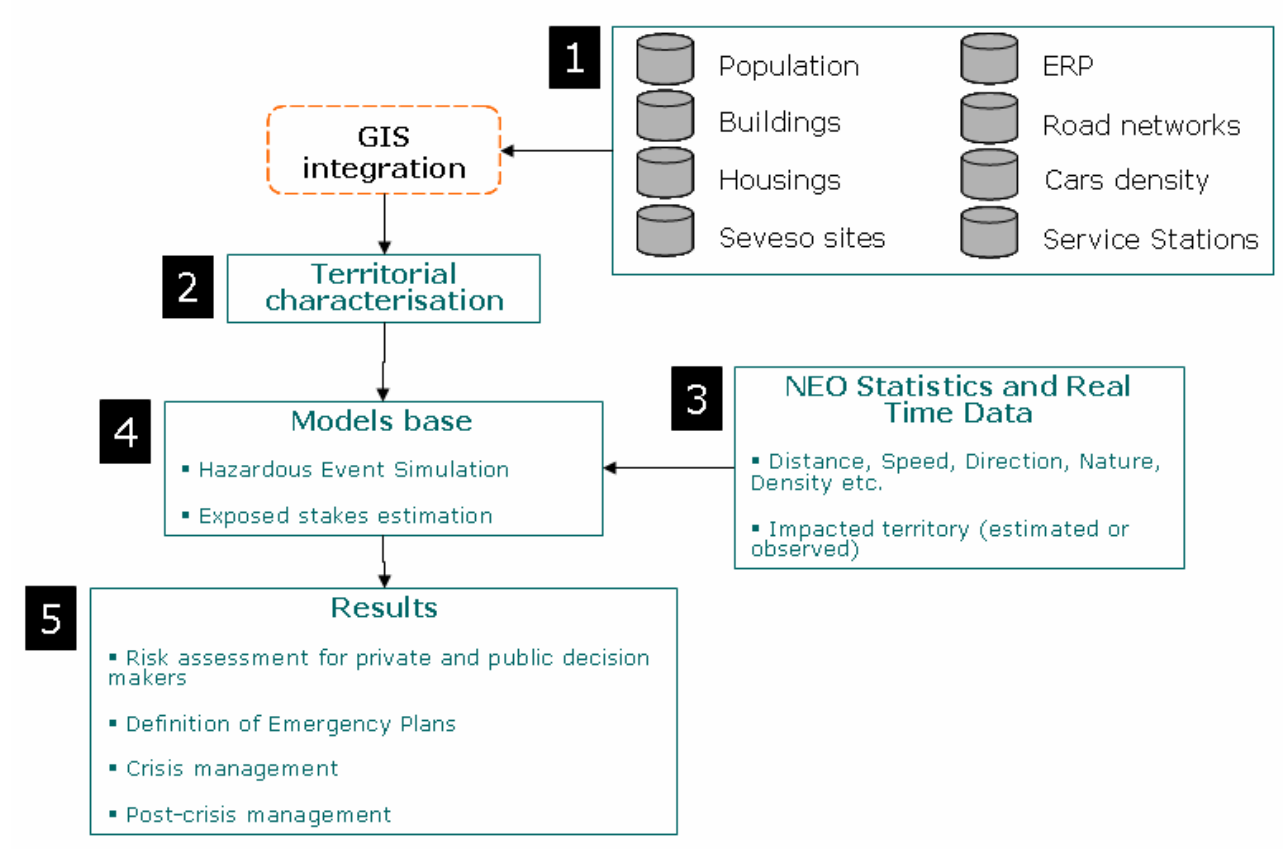

Fig. 1. SDSS dedicated to the vulnerability assessment and mitigation for a territory facing the risk and/or the consequences of a small celestial body impact.

effects. These results are determinant for the Civil Protection because they provide information to scale the means to organise the emergency (evacuation, intervention, exclusion, sanitary restrictions).

The next paragraph proposes a case study of four small NEO impacts on the French territory in order to demonstrate the consequences of such an event and the interest of this SDSS prototype.

\section{Scenarios and results of damage assessment}

\subsection{Selected territory for the case study}

The city of Nice is situated in the South-East part of France, in the department of the "Alpes-Maritimes" which harbours the French Riviera (Fig. 2). Nice is the 5th city of France by its population (around 350000 inhabitants) and it is situated between the Mediterranean sea and the mountains (Mercantour's chain). The surface of the city is $71.92 \mathrm{~km}^{2}$. Due to these topographic and environmental constraints, the city of Nice is a dense urbanised area. The main activity in Nice is the tourism industry which is supported by the presence of an international airport and port, railway and highway infrastructures, recreational places and more than 400 hotels.

We have chosen this city not only because it represents a medium French city with many stakes, but also because we can model its territory using accurate spatial databases. Figure 2 shows the location of the main infrastructure of the city and the potential sources of domino effects like the small industries and the service stations that provide different kinds of fuels (gasoline, diesel, LPG, etc.).

The next step consists of the determination of the hazardous distances after the impact of a small celestial body in the centre of the city of Nice. These simulation results, in turn, will be integrated into the GIS platform in order to extract the impacted stakes.

\subsection{Scenarios of NEO impacts}

The numbers of bodies in the range of sizes from 10s to 100 s of metres in diameter that enter the top of the Earth's atmosphere is fairly well estimated (Bland and Artemieva, 2006; Harris 2009), but the number that actually makes it through the atmosphere and strikes the ground is very uncertain. In particular, the survival of the body depends on its physical properties (e.g., iron material is more resistant to the atmosphere entry than a rocky one and, therefore, smaller iron bodies than rocky ones can reach the ground; Bland and Artemieva, 2006), and also on its orientation when it enters the atmosphere (ref.). Until recently, it was thought that a rocky body smaller than a few tens of metres would break up in the atmosphere and not actually strike the ground. Following such an explosion close to the surface, a resulting airblast would be transmitted to the ground, and could create substantial damage. That is what is thought to have happened in the 1908 Tunguska event: a rocky meteorite of maybe 20-30 m diameter catastrophically disrupted at an altitude of $5-10 \mathrm{~km}$ and the resulting airblast destroyed an area of 

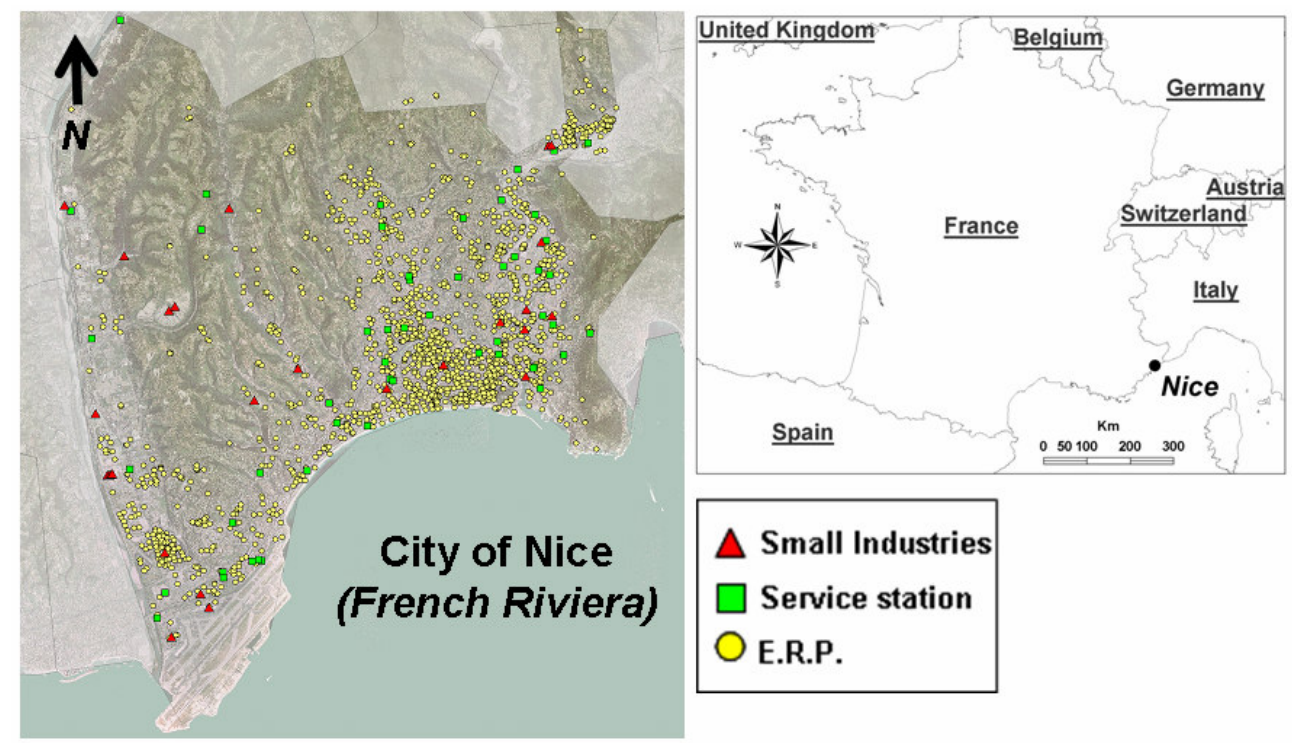

Fig. 2. Location of the main stakes and infrastructures of Nice, France.

$2000 \mathrm{~km}^{2}$ of forest. The energy of that event was equivalent to a 10-20 Megaton nuclear bomb, comparable to the largest nuclear bombs tested. But for rocky bodies less than about $20 \mathrm{~m}$, it was thought, until recently, that the atmosphere protected the surface from harm. It was also thought that metallic objects as small as a few metres could strike the ground, but those metallic asteroids are estimated to represent a very small fraction of the total number of near Earth asteroids.

But a recent event contradicts the conventional wisdom. In September 2007, what was apparently a $1-2 \mathrm{~m}$ rocky body actually impacted the surface in Peru at a speed of 3$5 \mathrm{~km} \mathrm{~s}^{-1}$ (Tancredi et al., 2009). It blasted out a crater about $15 \mathrm{~m}$ in diameter. The overpressure at a distance of $100 \mathrm{~m}$ was estimated to be around of $1.30 \times 10^{5}$. Usually, such sized bodies enter the Earth's atmosphere about once a year to once a decade, and mostly blow up in the high atmosphere (as the small body 2008 TC3 did in October 2008; Jenniskens et al., 2009). Although the Peru event was demonstrably a very unusual, perhaps singular, event that does not really alter the statistical risks much (if at all), how a body of such a small size could reach the ground remains a mystery. Moreover, recent simulations of atmosphere entry of rocky bodies showed the outcome of such an entry is highly sensitive to the actual orientation of the semi-axes (assuming an ellipsoidal shape) of the body at the entry point. Therefore, the size of the body impacting the Earth may differ from one case to the other depending on many sensitive parameters that are not easy to determine in advance, explaining the sometimes unexpected or unusual events, such as the one in Peru.

So for the estimates here, we shall consider small rocky bodies (assumed density of $3 \mathrm{~g} \mathrm{~cm}^{-3}$ ) entering the top of the atmosphere at a typical velocity of $20 \mathrm{~km} \mathrm{~s}^{-1}$ with an angle of incidence of $45^{\circ}$. If the body has a size of $30 \mathrm{~m}$ or larger, we simply assume that it does neither vaporize nor fragment into smaller pieces and that it is only slowed by the atmospheric drag as appropriate for its size. For the $20 \mathrm{~m}$ bodies, we assume that $5 \%$ would be equivalent to metallic ones and, therefore, reach the ground and assume, arbitrarily, that another $15 \%$ make it to the ground although they are rocky, so their frequency is reduced accordingly to $20 \%$ total of those at the upper atmosphere.

The uncertainty in these estimates makes it clear that there is a lot to be learned about the $100 \mathrm{~m}$ and smaller bodies and their interaction with the atmosphere and the Earth. For instance, which unusual conditions made a 1-2 m rocky object hit in Peru? Was the Tunguska impactor as small as $20 \mathrm{~m}$ ? Those questions remain open (Hills and Goda, 1993). Here, no attempt was made to account for atmospheric airburst (except for lowering the surface impact frequency estimates for the $20 \mathrm{~m}$ bodies), for tsunamis created by off-shore impacts or other possibly consequential effects. The damage is based only on an explosive-equivalent airburst. But the present purposes are to demonstrate a method for the risk estimation and, therefore, the actual numbers are not so important. Future work is planned to refine these first estimates of damage areas.

Table 1 presents the four scenarios and results of impact simulations on the territory of the city of Nice. For each case it is assumed that a rocky object strikes the ground (hard rock) in which results in the formation of a crater and blast effects. The initial velocity of the object has been chosen as $20 \mathrm{~km} \mathrm{~s}^{-1}$ with a $45^{\circ}$ trajectory. Each scenario, from $\mathrm{S} 1$ to $\mathrm{S} 4$, is characterised by the following parameters: the impactor diameter, the population dimension of this kind of asteroid in the Earth-crossing zone, the impact frequency on Earth, its probability per year to hit the French 
Table 1. Impact effects simulations according to four scenarios of NEO.

\begin{tabular}{lllll}
\hline Meteorite or fragment Diameter & $\mathrm{S} 1$ & $\mathrm{~S} 2$ & $\mathrm{~S} 3$ & $\mathrm{~S} 4$ \\
& $20 \mathrm{~m}$ & $30 \mathrm{~m}$ & $50 \mathrm{~m}$ & $70 \mathrm{~m}$ \\
\hline $\begin{array}{l}\text { Number that size or larger known in } \\
\text { near-Earth orbits }\end{array}$ & 100000000 & 1500000 & 700000 & 200000 \\
\hline Estimated Frequency of Earth impact & Once per $250 \mathrm{yr}$ & Every $300 \mathrm{yr}$ & Every $900 \mathrm{yr}$ & Every $2000 \mathrm{yr}$ \\
\hline Odds of hitting France, per year & $5 \times 10^{-6}$ & $4 \times 10^{-6}$ & $1.4 \times 10^{-6}$ & $6 \times 10^{-7}$ \\
\hline Initial Energy & $0.7 \mathrm{Mtons}$ & $2 \mathrm{Mtons}$ & $9 \mathrm{Mtons}$ & $25 \mathrm{Mtons}$ \\
\hline Velocity at impact & $17.5 \mathrm{~km} \mathrm{~s}-1$ & $18.3 \mathrm{~km} \mathrm{~s}{ }^{-1}$ & $18.9 \mathrm{~km} \mathrm{~s}-1$ & $19.3 \mathrm{~km} \mathrm{~s}$ \\
\hline Energy of Impact & $0.5 \mathrm{Mtons}$ & $1.7 \mathrm{Mtons}$ & $8 \mathrm{Mtons}$ & $23 \mathrm{Mtons}$ \\
\hline Crater Diameter & $300 \mathrm{~m}$ & $450 \mathrm{~m}$ & $700 \mathrm{~m}$ & $933 \mathrm{~m}$ \\
\hline Crater Depth & $80 \mathrm{~m}$ & $120 \mathrm{~m}$ & $190 \mathrm{~m}$ & $255 \mathrm{~m}$ \\
\hline Mass ejected & $8 \mathrm{Mtons}$ & $23 \mathrm{Mtons}$ & $84 \mathrm{Mtons}$ & $200 \mathrm{Mtons}$ \\
\hline Richter Scale Energy & 5.5 & 6.0 & 6.3 & 6.6 \\
\hline $\begin{array}{l}\text { Distance to tree blowdown, building } \\
\text { destruction }\left(2.76 \times 10^{4} \mathrm{~Pa}\right)\end{array}$ & $4 \mathrm{~km}$ & $6 \mathrm{~km}$ & $10 \mathrm{~km}$ & $14 \mathrm{~km}$ \\
\hline
\end{tabular}

territory, the initial kinetic energy of the asteroid, its velocity at ground zero, the impact energy, the final crater diameter and depth, the amount of ejected mass, the evaluation of the Richter scale energy and the distance within which the wind (blast effect) is greater than $50 \mathrm{~m} \mathrm{~s}^{-1}$ and the blast pressure is $2.76 \times 10^{4} \mathrm{~Pa}(4 \mathrm{psi})$, the number commonly used to blow down trees and make major damages to buildings. For the cratering process and subsequent mass thrown out, these estimates are based on the comprehensive impact cratering database that is incorporated into a sophisticated online tool (see the following Internet site: (Holsapple, http: //keith.aa.washington.edu/craterdata/scaling/index.htm); for the airblast, estimates are based on the nuclear bomb airblast science for a surface burst described in Glasstone and Dolan (1977). The equivalent earthquake is based on an energy equivalence between an impact and an earthquake.

The following figure (Fig. 3) shows the mapping of the affected areas in the centre of the city of Nice.

Note that the scaling of the cratering process from ground and laboratory experiments to the scales of an asteroid impact is still an entire field of research and, therefore, error bars remain quite large regarding the outcome of a small body impact from the extrapolation of the known outcomes at smaller scales. So-called scaling laws have been developed for this purpose (see e.g., Melosh, 1989; Holsapple, 1993), and here we use the ones developed by Holsapple (1993) that are often considered as the state-of-the-art in this field. However, many parameters that influence the cratering outcome are not necessarily well measured (in particular, the material properties of the projectile and impacted surface) and, therefore, our analysis does not pretend to represent with great accuracy the consequences of the impact at the considered impact energy. Our aim is rather to show that with the current knowledge (which, although still uncertain, gives some ranges of potential consequences), we can establish for a given region for which a complete database of infrastructures exists (hence, the subjective choice of Nice), the level of damage that can be expected. The next paragraph presents the results of these damage estimates for different scenarii.

\subsection{Results}

The damage estimates caused by a small body impacts at a given impact energy are constrained by the following data:

- The number of buildings: this information comes from the IGN (French National Institute of Geography) and represents the geometry in two dimensions of all buildings. This layer was kindly provided by the city of Nice.

- The INSEE IRIS Habitat file (French National Institute for Statistics and Economical Studies) provides data related to the housing, the number of cars, the number of dwellings and their average area for each building, and the amount of people for each dwelling.

- The service stations, Establishments Receiving Public (ERP) and small industries: theses layers have been kindly provided by the city of Nice. They show the location of each element and, for the ERP, it is possible to know precisely the nature of the Establishment, i.e., cult 


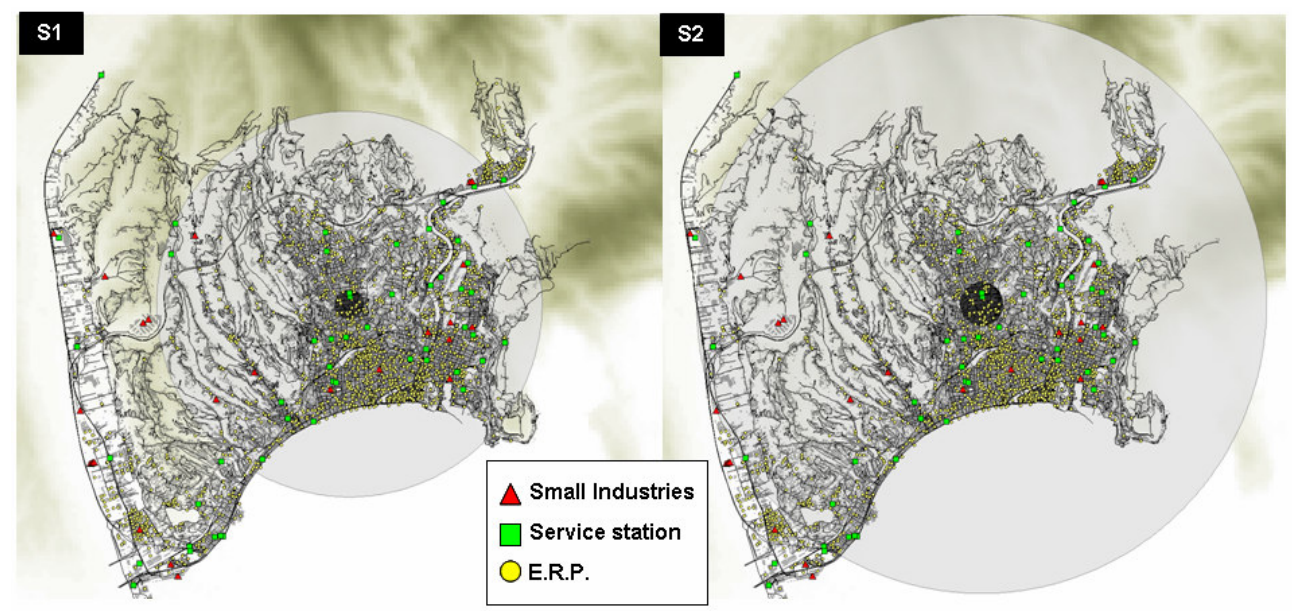

Fig. 3. Mapping of the destruction distances according to the first two scenarios of small rocky body impacts in the centre of Nice's city. The crater diameter (black circle) and the distance where the airblast effect is superior to $2.76 \times 10^{4}$ is this (grey circle) have been considered as the reference distances within which buildings and infrastructures are destroyed. It is also assumed that the ejected mass participates in the destruction of buildings and infrastructures for each calculated distance.

Table 2. Amount of exposed stakes.

\begin{tabular}{rrrrrrrrr}
\hline & $\begin{array}{r}\mathrm{Nb} \\
\text { Buildings }\end{array}$ & $\begin{array}{r}\mathrm{Nb} \\
\text { Housings }\end{array}$ & $\begin{array}{r}\text { Housing } \\
\text { Surfaces }\left(\mathrm{m}^{2}\right)\end{array}$ & Cars & Population & $\begin{array}{r}\text { Nb Service } \\
\text { Stations }\end{array}$ & $\begin{array}{r}\text { Nb ERP } \\
\text { Industries }\end{array}$ & Nb \\
\hline S1 & 38491 & 180108 & 11265341 & 106656 & 274226 & 38 & 1768 & 13 \\
S2 & 50541 & 209693 & 13254063 & 130611 & 325545 & 46 & 2060 & 17 \\
S3 & 52052 & 215008 & 13704070 & 134770 & 338570 & 52 & 2227 & 26 \\
S4 & $>52052$ & $>215008$ & $>13704070$ & $>134770$ & $>338570$ & $>52$ & $>2227$ & $>26$ \\
\hline
\end{tabular}

Table 3. Cost for building reconstructions and car compensations.

\begin{tabular}{rrrr}
\hline & $\begin{array}{r}\text { Cost for } \\
\text { reconstruction }\end{array}$ & $\begin{array}{r}\text { Cost for cars } \\
\text { compensation }\end{array}$ & Total \\
\hline S1 & 17956953221 & 1202123851 & 19159077072 \\
S2 & 21126976093 & 1472118969 & 22599095061 \\
S3 & 21844287580 & 1518992670 & 23363280250 \\
S4 & $>21844287580$ & $>1518992670$ & $>23363280250$ \\
\hline
\end{tabular}

establishments, schools, hospitals, stadium, services of the city, etc.

Table 3 presents the cost of each scenario taking into account the following individual costs (excluding the estimation of compensations caused by the loss of people, as it varies quite widely from one insurer to the other):

- the average price of building construction given by the INSEE;
- the cost of car compensations estimated by the Committee of the French Automobiles Constructors and the French Federation of Insurance Companies.

According to the magnitude of the event and the vulnerability of the considered territory, the conclusions of these results are:

1. A $20 \mathrm{~m}$ or $30 \mathrm{~m}$ rocky body impact (S1 or $\mathrm{S} 2$ ) would provoke the destruction of almost the entire city of Nice with the loss of 325.000 people (S2). The cost of such an event would reach twenty one billion Euros, which represents $9 \%$ of the capital of the 40 largest reinsurance companies in the world (Standard and Poors, 2008) and exceeds the capital of the French Central Fund of Reinsurance. Almost all life support networks (water, gas, electricity, communication, transport and medical network, etc.) of the city would collapse, causing an aggravation of the situation because of the disorganization of the public emergency means. In the few minutes after the event, domino effects would occur due to the presence on the territory of service stations, small 
industries that contain hazardous material, and the gas network (propane) managed by the municipality.

2. The two other scenarii underline that the city of Nice would be completely destroyed and, in these two cases, the hazardous effects would destroy other stakes in the nearby municipalities.

Due to the estimated frequencies of such small body impacts on Earth (e.g., once per $250 \mathrm{yr}$ for a $20 \mathrm{~m}$ body), although the probability that it occurs over a populated area remains small, it is possible that insurance and reinsurance companies will have to consider or face this kind of threat in the future. In this case, this SDSS can be transposed in order to help the decision makers to take into account this natural hazard and to prepare prevention and reconstruction strategies to mitigate their territorial vulnerability.

\section{Conclusions}

Starting from the definition of the territorial vulnerability originating from the impact of a Near Earth Object (NEO), this paper proposes a prototype of Spatial Decision Support System (SDSS) dedicated to the different decision makers involved into the mitigation and reparation of such an event. Applied to a dense urbanised and well-described territory, this SDSS has shown that small NEOs (less than $100 \mathrm{~m}$ of diameter) can significantly affect the territory with relevant economical consequences for the insurance and reinsurance companies expressed by the exposure of insurance portfolios. This economical damage assessment takes into account the price of reconstruction of buildings and car compensation that can be insured by those companies. One of the improvements of this assessment will be the integration of the average capital value for people killed in order to complete the estimation. In this case, it would be useful to initiate a work programme with all the public actors in the disaster management induced by the impact of a small NEO. This work programme might constitute a reflection frame to help the insurance and reinsurance companies to define their strategy to face such a threat. Another improvement of this SDSS would be its ability to estimate the vulnerability of the infrastructures and buildings related to seismic waves, and to take into account the modelling of submersion waves caused by the impact of a small body into the marine surfaces (tsunami model).

From the point of view of the whole territorial vulnerability, the SDSS takes into account the number of people killed, and other stakes like hotels, industries, public transportation, etc. These results are dedicated to the public entities that have to organise the territory, regulate the activities and provide support for crisis management and post-crisis rehabilitation. According to the organisation of the French territory and the role of each public decision maker in the case of the risk of small NEO impact, the contribution of the SDSS can be considered for the following issues:

- the awareness of public and private decision makers;

- the definition of mitigation strategies and Emergency Planning based on the scenarii, especially for detected potentially hazardous NEOs;

- the organisation of training sessions to check the efficiency of the Emergency Planning;

- the crisis management with the use of real-time data;

- the post-crisis management to estimate the cost and to optimize the strategy for reparation and compensation actions.

Because of the complexity of our societies, the globalisation of the economical exchanges and the interrelationships between the countries, this kind of reflection frame proposed with this SDSS should be transposed to other countries and should involve international organisations like the United Nations Organisation (United Nations Organisation, International Strategy for Disaster Reduction: http://www. unisdr.org) to support its reflection in terms of governance for risks induced by NEO.

Acknowledgements. The authors wish to express their acknowledgments to the insurance Company "La MAIF" which supported this study and to the city of Nice for the geographical data provided. The authors are grateful to K. A. Holsapple, University of Washington, for his fruitful suggestions and for providing the scaling laws allowing the determination of the crater size as a function of impact conditions.

Edited by: A. Costa

Reviewed by: A. W. Harris and P. Paolicchi

\section{References}

Alvarez, L. W., Alvarez, W., Asaro, F., and Michel, H. L.: Extraterrestrial cause for the Cretaceous-Tertiary Extinction. Science, New Series, 208, 4448, 1095-1108, 1980.

Bland, P. A. and Artemieva, N. A.: The impact of small asteroids, Meteorit Planet. Sci., 41, 607-631, 2006.

Boslough, M.: The Nature of Airbursts and their Contribution to the Impact Threat, 1st IAA Planetary Defense Conference: Protecting Earth from Asteroids, 27-30 April 2009, Granada, Spain, 2009.

Bottke, W.: Understanding the Near-Earth Object Population: the 2004 Perspective, in Comet/Meteorite impacts and Human Society: An Interdisciplinary Approach, edited by: Bobrowsky, P. T. and Rickman, H., 175-187, 2007.

Brooks, N.: Vulnerability, risk and adaptation: A conceptual framework. Tyndall Centre for Climate Change Research Working Paper 38, 16, 2003. 
Chapman, C. R.: How a Near-Earth Object Impact Might Affect Society, Workshop on Near Earth Objects: Risks, Policies, and Actions, OCDE, January 2003, Frascati, Italy, 25, 2003.

Chevallier, J. J.: Système d'aide à la décision à référence spatiale, MoSIT, 2, 11-15, 1994.

Chevallier, J. J.: Systèmes d'aide à la décision à référence spatiale (SADRS): méthode de conception et de développement, Actes de congres GIS/SIG'93, Ottawa, 23-25 mars 1993.

Chyba, C. F., Thomas, P. J., and Zahnle, K. J.: The 1908 Tunguska explosion: atmospheric disruption of a stony asteroid, Nature, 361, 40-44, 1993.

Crichton, D.: The risk triangle, in: Natural Disaster Management, edited by: Ingleton, J., Tudor Rose, London, 102-103, 1999.

French, B. M.: Traces of Catastrophe: A Handbook of ShockMetamorphic Effects in Terrestrial Meteorite Impact Structures, Lunar and Planetary Institute, Contribution No. 954, Houston, 120, 1998.

Garbolino, E., Michel, P., and Holsapple, K: Insurance and Meteor Falls: Proposal of a Methodology for Estimating the Risk and Modelling Consequences for the Insurance Sector in France, 1st IAA Planetary Defense Conference: Protecting Earth from Asteroids, 27-30 April 2009, Granada, Spain, 2009.

Glasstone, S. and Dolan, P.: The Effects of Nuclear Weapons, 3d Edition, US Department of Defense, 653 pp., 1977.

Harris, A. W.: Estimating the NEO Population and Impact Risk: Past, Present and Future, 1st IAA Planetary Defense Conference: Protecting Earth from Asteroids, 27-30 April 2009, Granada, Spain, 2009.

Hills, J. G. and Goda, M. P.: Damage from the impact of small asteroids, Planet Space Sci., 46(2/3), 219-229, 1998.

Hills, J. G. and Goda, M. P.: The fragmentation of small asteroids in the atmosphere, Astron J., 105, 1114-1144, 1993.

Holsapple, K. A.: The Scaling of Impact Processes in Planetary Sciences, Annu Rev. Earth Pl. Sc., 21, 333-373, 1993a.

Holsapple, K. A.: The Size of Complex Craters, Lunar and Planetary Science, 24, 665-666, 1993b.

Holsapple, K. A.: Crater Sizes from Explosion and Impacts, http: //keith.aa.washington.edu/craterdata/scaling, 2003.
Jenniskens P., Shaddad M. H., Numan D., Elsir, S., Kudoda, A.M., Zolensky, M. E., Le, L., Robinson, G. A., Friedrich, J. M., Rumble, D., Steele, A., Chesley, S. R., Fitzsimmons, A., Duddy, S., Hsieh, H. H., Ramsay, G., Brown, P. G., Edwards, W. N., Tagliaferri, E., Boslough, M.B., Spalding, R. E., Dantowitz, R., Kozubal, M., Pravec, P., Borovicka, J., Charvat, Z., Vaubaillon, J., Kuiper, J., Albers, J., Bishop, J. L., Mancinelli, R. L., Sandford, S. A., Milam, S. N., Nuevo, M., and Worden, S. P.: The impact and recovery of asteroid 2008 TC3, Nature, 458, 485488, 2009.

Melosh H. J.: Impact Cratering - A Geological Process, Oxford University Press, New York, 1989.

Michel, P., Morbidelli, A., and Bottke, W.: Origin and dynamics of Near Earth Objects. CR Phys., 6, 291-301, 2005.

Morrison, D., Harris, A. W., Sommer, G., Chapman, C. R., and Carusi, A.: Dealing with the impact hazard, in Asteroids III, William Bottke, Alberto Cellino, Paolo Paolicchi, and Richard P. Binzel editors, University of Arizona Press, Tucson, 739-754, 2002.

Morrison, D.: The Impact Hazard: Advanced NEO Surveys and Societal Responses, in Comet/Meteorite impacts and Human Society: An Interdisciplinary Approach, edited by: Bobrowsky, P. T. and Rickman, H., 163-173, 2007.

Poveda, A., Herrera, M. A., Garcia, J. L., and Curioca, K.: The diameter distribution of Earth-crossing asteroids, Planet and Space Sci, 47, 679-685, 1999.

Schweickart, R. L., Jones, T. D., von der Dunk, F., and CamachoLara, S.: Asteroid threats: A call for global response, ASSE, NEOC, Jessica Tok Editor, 54, 2008.

Tancredi, G., Ishitsuka, J., Schultz, P., Harris, S., Brown, P., and ReVelle, D.: The Carancas Event: a Recent Hypervelocity Impact Crater in the Altiplano, 1st IAA Planetary Defence Conference, Granada, 27-30 April 2009, Granada, Spain, 2009.

Toon, O. B., Turco, R. P., and Covey, C.: Environmental perturbations caused by the impacts of asteroids and comets. Rev. Geophy., 35(1), 41-78, 1997.

United Nations Organisation: International Strategy for Disaster Reduction: http://www.unisdr.org, 2004.

Valsecchi, G. and Milani Comparetti, A.: Evaluating the Risk of Impacts and the Efficiency of Risk Reduction, in: Comet/Meteorite impacts and Human Society: An Interdisciplinary Approach, edited by: Bobrowsky, P. T. and Rickman, H., 203-210, 2007. 